\title{
Decreased expression of TLR7 in gastric cancer tissues and the effects of TLR7 activation on gastric cancer cells
}

\author{
JIONG JIANG, LEI DONG, BIN QIN, HAITAO SHI, XIAOYAN GUO and YAN WANG \\ Department of Gastroenterology, Second Affiliated Hospital of Xi'an Jiaotong University, Xi'an, Shanxi 710003, P.R. China
}

Received December 24, 2014; Accepted January 26, 2016

DOI: $10.3892 / \mathrm{ol} .2016 .4617$

\begin{abstract}
The present study aimed to determine the expression of Toll-like receptor 7 (TLR7) in gastric cancer tissues and investigate the effects of its activation on gastric cancer cells. Patients with gastric cancer $(n=30)$ and patients without gastric cancer (control; $n=14$ ) who underwent gastroscopy were enrolled in the study. Gastric cancer and cancer-adjacent tissues were obtained from the patients with gastric cancer, and normal gastric epithelial tissues were obtained from the control patients. The TLR7 mRNA and protein expressions in different tissues were investigated by reverse transcription-quantitative polymerase chain reaction, western blotting and immunohistochemistry. The present study also determined the effects of TLR7 activation by the agonist imiquimod on TLR7 protein expression, proinflammatory cytokine secretion and viability in SGC-7901 gastric cancer cells. The mRNA and protein expression levels of TLR7 were significantly downregulated in gastric cancer tissues compared with cancer-adjacent and normal gastric epithelial tissues $(\mathrm{P}<0.01)$. Imiquimod significantly increased TLR7 protein expression levels, and promoted the secretion of proinflammatory cytokines tumor necrosis factor- $\alpha$ and interleukin-6 in SGC-7901 cells. Furthermore, imiquimod inhibited the proliferation of SGC-7901 cells in a dose- and time-dependent manner. Thus, the present study identified that the expression of TLR7 was decreased in gastric cancer tissues, and TLR7 activation enhanced TLR7 expression, promoted the production of proinflammatory cytokines and inhibited the growth of gastric cancer cells.
\end{abstract}

\section{Introduction}

Toll-like receptors (TLRs) comprise an important family of pattern recognition receptors that result in the stimulation of innate and adaptive immunity. TLRs form part of the first line of defense against microbial infection (1). Functional TLRs are

Correspondence to: Dr Lei Dong, Department of Gastroenterology, Second Affiliated Hospital of Xi'an Jiaotong University, 157 Xi'wu Road, Xi'an, Shanxi 710003, P.R. China

E-mail: leidongcn@163.com

Key words: gastric cancer, Toll-like receptor-7 expression, SGC-7901 cells expressed not only in immune cells, but also in certain types of cancer cells (2-5). Activated TLRs in cancer cells are able to upregulate $\mathrm{NF}-\kappa \mathrm{B}$ signaling cascade and induce the expression of anti-apoptotic proteins that lead to cancer cell proliferation. Furthermore, TLRs can increase the production of pro-inflammatory cytokines and chemokines that recruit immune cells to promote an immunosuppressive microenvironment, induce gene mutation or angiogenesis, and further contribute to tumor progression (6). By contrast, functional TLRs can also induce programmed cell death, strengthening immune surveillance and enhancing chemosensitivity $(7,8)$. These results suggest that TLRs may provide dual effects on cancer cells, and their major roles may depend on tumor origin and TLR type.

Gastric cancer is the fourth most common type of cancer in the world and is highly prevalent in Asia; of 988,000 novel cases of gastric cancer, $45 \%$ are identified in China $(9,10)$. The incidence and mortality of gastric cancer in China are 36.21 and 26.88 per 10 million individuals, respectively (11). In the past few decades, the mortality rate of gastric cancer has decreased in numerous areas of the world, due to the availability of screening for early detection and improved treatments (12). However, the resistance to chemotherapy and tumor recurrence continue to make this disease the second leading cause of cancer-associated mortality worldwide (13). For these reasons, the identification of novel prognostic factors and development of more effective drugs has become a new direction in gastric cancer treatment. Accumulating evidence suggests that the chronic inflammation caused by microbial infection is an important risk factor correlated with the aberrant proliferation of gastric cancer cells. TLRs exert a crucial role in the induction and progression of chronic inflammation (14). These receptors recognize conserved molecular patterns expressed in infectious agents, and mediate the production of pro-inflammatory cytokines and chemokines. Various TLRs, such as TLR2, TLR4, TLR5 and TLR9, have been reported to be expressed in gastric cancer cells (15); however, little is known about the expression of TLR7 in gastric cancer cells. TLR7 is an endosomal TLR that is primarily located in intracellular vesicles, such as endoplasmic reticulum, endosomes, lysosomes and endolysosomes. Furthermore, the activation of TLR7 has potent anti-tumor effects by mediating immune activation and programmed cell death in various types of cancer cell, such as colon cancer cells (16). However, the role of TLR7 on gastric cancer cell growth remains unknown. The objective of the present study was to determine the mRNA and 
protein expression levels of TLR7 in gastric cancer tissues, and their association with the clinicopathological characteristics of gastric cancer. The effects of TLR7 activation on human gastric cancer cells were also investigated.

\section{Subjects and methods}

Subjects. Patients with gastric cancer $(n=30)$ and healthy patients without gastric cancer (control; $n=14$ ) who underwent gastroscopy in the Department of Gastroenterology, Second Affiliated Hospital of Xi'an Jiaotong University (Xi'an, China) between July 2010 and August 2011 were enrolled in the present study. The basal characteristics of the two groups are summarized in Table I. No patient received pre-operative radiotherapy or chemotherapy. The gastric cancer and cancer-adjacent tissues were obtained from patients with gastric cancer, and the normal gastric epithelial tissues were obtained from the control patients. Ethical approval for tissue use in the present study was obtained from the Human Subjects Committee of Xi'an Jiaotong University and written informed consent was obtained from all subjects. All specimens were immediately frozen in liquid nitrogen for at least $1 \mathrm{~h}$ and then stored at a temperature of $-80^{\circ} \mathrm{C}$ until use. No significant difference in gender, age, smoking, drinking or Helicobacter pylori infection was observed between the gastric cancer and control patients.

Immunohistochemistry. The gastric cancer and cancer-adjacent tissues were embedded in paraffin (Sigma-Aldrich, St. Louis, MO, USA). The paraffin-embedded tissues were cut into $4-\mu \mathrm{m}$ thick sections, deparaffinized with xylene (Sigma-Aldrich) and rehydrated in ethyl alcohol (Sigma-Aldrich). For blocking endogenous peroxidase activity and antigen retrieval, the sections were treated with $3 \%$ hydrogen peroxide (Sigma-Aldrich), followed by microwaving at $95^{\circ} \mathrm{C}$ for $15 \mathrm{~min}$. Sections were incubated with rabbit anti-human TLR7 polyclonal antibody (1:50 dilution; catalog no., ab45371; Abcam, Cambridge, MA, USA) at $4^{\circ} \mathrm{C}$ overnight then washed with phosphate-buffered saline (PBS; Fuzhou Maixin Biotechnology Development Co., Ltd., Fuzhou, China). Controls were incubated with PBS in place of primary antibody. Then the sections were treated with goat anti-rabbit secondary antibody (1:100 dilution; catalog no., MX10043; Fuzhou Maixin Biotechnology Development Co., Ltd.) using SuperPicture Polymer Detection kit (Zymed; Thermo Fisher Scientific, Inc. Waltham, CA, USA) and 3,3'-diaminobenzidine (Invitrogen; Thermo Fisher Scientific, Inc.), according to the manufacturer's protocol. The sections were observed using a Q550CW image acquisition and analysis system (Leica Microsystems $\mathrm{GmbH}$, Wetzlar, Germany). In total, 4-5 fields of view in each slice were selected and measured, and the integral optical density (IOD) of TLR7 protein expression was calculated.

Reverse transcription-quantitative polymerase chain reaction (RT-qPCR). Total RNA was extracted from each biopsies sample using an RNA Fast 200 kit (Shanghai Fastagen Biotech Co., Ltd., Shanghai, China) in accordance with manufacturer's protocol. mRNA was reverse-transcribed with RevertAid First Strand cDNA Synthesis kit (Thermo Fisher Scientific, Inc.) at $37^{\circ} \mathrm{C}$ for $15 \mathrm{~min}$ and stopped at $85^{\circ} \mathrm{C}$ for $5 \mathrm{sec}$. RT-qPCR was performed in a final volume of $20 \mu \mathrm{l} \mathrm{SYBR}$ Green PCR mixture (Applied Biosystems; Thermo Fisher Scientific, Inc.). The PCR conditions were as follows: Preliminary denaturation at $94^{\circ} \mathrm{C}$ for $3 \mathrm{~min}$, followed by 40 cycles of $95^{\circ} \mathrm{C}$ for $20 \mathrm{sec}$, $60^{\circ} \mathrm{C}$ for $20 \mathrm{sec}$ and $72^{\circ} \mathrm{C}$ for $20 \mathrm{sec}$. All cDNA samples were analyzed in duplicate. $\beta$-actin was used as a normalization control in RT-qPCR. The TLR7 mRNA expression ratio was calculated as the fold-expression of TLR7 relative to $\beta$-actin using $2^{-\Delta \Delta \mathrm{Cq}}$ (17). The primer sequences used for amplification were as follows: Upstream, 5'-AAACTCTGTGATGTC-3' and downstream, 5'-GATGTCTGGTATGTGGTTAATGG-3' for TLR7; upstream, 5'-ATCGTGCGTGACATTAAGGAG AAG-3' and downstream, 5'-AGGAAGGAAGGCTGGAAG AGTG-3' for $\beta$-actin.

TLR7 activation and cell viability assay. SGC-7901 human gastric cancer cells were obtained from the Cell Bank of Chinese Academy of Sciences (Shanghai, China), and maintained in RPMI-1640 medium (Invitrogen; Thermo Fisher Scientific, Inc.) containing $10 \%$ of fetal bovine serum (Invitrogen; Thermo Fisher Scientific, Inc.), $100 \mathrm{U} / \mathrm{ml}$ penicillin (Fuzhou Maixin Biotechnology Development Co., Ltd.) and $100 \mu \mathrm{g} / \mathrm{ml}$ streptomycin (Fuzhou Maixin Biotechnology Development Co., Ltd.) at $37^{\circ} \mathrm{C}$ in a humidified incubator containing $5 \% \mathrm{CO}_{2}$. Cells were seeded in 96-well plates at $5 \times 10^{3}$ cells/well, and then exposed to $0,1.5,3.125,6.25,12.5$, $25,50,100$ or $200 \mu \mathrm{g} / \mathrm{ml}$ of the TLR7 agonist imiquimod (Enzo Life Sciences International, Inc., Plymouth Meeting, PA, USA) for various time periods $(12,24,48,72 \mathrm{~h})$. Following treatment, $20 \mu \mathrm{l}$ MTT (5 mg/ml; Sigma-Aldrich) was added to each well and the plates were re-incubated at $37^{\circ} \mathrm{C}$ for $4 \mathrm{~h}$. Subsequent to centrifugation at $800 \mathrm{x} \mathrm{g}$ for $5 \mathrm{~min}$, the supernatant was carefully removed and the product was dissolved in $150 \mu \mathrm{l}$ dimethyl sulfoxide (Sigma-Aldrich), followed by shaking for $5 \mathrm{~min}$. The absorbance of the solution was measured at $490 \mathrm{~nm}$ using a microtiter plate reader (BD176863; BD Biosciences, Franklin Lakes, NJ, USA). All experiments were performed in triplicate.

Measurement of cytokines. SGC-7901 cells were seeded in 6-well plates and incubated overnight. The cells were treated with $100 \mu \mathrm{g} / \mathrm{ml}$ imiquimod for $24 \mathrm{~h}$. Subsequent to centrifugation at $1,000 \mathrm{x}$ g for $5 \mathrm{~min}$, the culture supernatant was collected for additional analysis. The control cells were not treated with imiquimod; they were instead treated with dimethyl sulfoxide (Sigma-Aldrich). The interleukin-6 (IL-6) and tumor necrosis factor- $\alpha$ (TNF- $\alpha$ ) concentrations in culture supernatant were determined using commercial enzyme-linked immunosorbent assay (ELISA) kits (MQ2-39C3; R\&D Systems Inc., Minneapolis, MN, USA), according to the manufacturer's protocol.

Western blot analysis. SGC-7901 cells were seeded in 6-well plates at $1 \times 10^{5}$ cells/well. Cells were lysed with radioimmunoprecipitation buffer on ice for $1 \mathrm{~h}$. The lysate was centrifuged $\left(15,000 \times \mathrm{g}, 4^{\circ} \mathrm{C}\right)$ for $30 \mathrm{~min}$ and then the supernatant was collected. The protein concentration was measured using a bicinchoninic acid protein assay kit (Thermo Fisher Scientific, Inc.), according to the manufacturer's protocol. Equal amounts of protein (20-30 $\mu \mathrm{g})$ were applied to the SDS-PAGE (10\% gel; $120 \mathrm{~V} ; 90 \mathrm{~min})$. Glyceraldehyde 3-phosphate dehydrogenase was used as the loading control. Following electrophoresis, the 
Table I. Basal characteristics of patients with gastric cancer $(n=30)$ and control patients $(n=14)$.

\begin{tabular}{|c|c|c|c|c|c|}
\hline \multirow[b]{2}{*}{ Characteristic } & \multicolumn{2}{|c|}{ Gastric cancer patients } & \multicolumn{2}{|c|}{ Control patients } & \multirow[b]{2}{*}{ P-value } \\
\hline & $\mathrm{n}$ & $\%$ & $\mathrm{n}$ & $\%$ & \\
\hline Gender & & & & & 0.583 \\
\hline Male & 22 & 73.3 & 10 & 71.4 & \\
\hline Female & 8 & 26.7 & 4 & 28.6 & \\
\hline Age & & & & & 0.315 \\
\hline$\geq 60$ years & 13 & 43.3 & 7 & 50.0 & \\
\hline$<60$ years & 17 & 56.7 & 7 & 50.0 & \\
\hline Smoking & & & & & 0.537 \\
\hline Yes & 14 & 46.7 & 6 & 42.8 & \\
\hline No & 16 & 53.3 & 8 & 57.1 & \\
\hline Drinking & & & & & 0.556 \\
\hline Yes & 18 & 60.0 & 8 & 57.2 & \\
\hline No & 12 & 40.0 & 6 & 42.8 & \\
\hline Helicobacter pylori & & & & & 0.603 \\
\hline Positive & 24 & 80.0 & 11 & 78.6 & \\
\hline Negative & 6 & 20.0 & 3 & 21.4 & \\
\hline
\end{tabular}

Table II. Mean integrated optical density of toll-like receptor 7 expression in different tissues.

\begin{tabular}{lcc}
\hline Group & $\mathrm{n}$ & Integrated optical density \\
\hline $\begin{array}{l}\text { Normal gastric } \\
\text { epithelial tissues }\end{array}$ & 14 & $0.6059 \pm 0.0609$ \\
Gastric cancer tissues & 30 & $0.4987 \pm 0.0607^{\mathrm{a}, \mathrm{b}}$ \\
$\quad$ Intestinal type & 19 & $0.4966 \pm 0.0634^{\mathrm{c}}$ \\
$\quad$ Diffuse type & 11 & $0.4955 \pm 0.0443$ \\
Cancer-adjacent tissues & 30 & $0.6191 \pm 0.0737^{\mathrm{d}}$ \\
\hline
\end{tabular}

Data are presented as mean \pm standard deviation. ${ }^{\mathrm{a}} \mathrm{P}<0.001 \mathrm{vs}$. normal gastric epithelial tissues; ${ }^{b} \mathrm{P}<0.001$ vs. cancer-adjacent tissues; ${ }^{\mathrm{c}} \mathrm{P}>0.05$ vs. diffuse type; ${ }^{\mathrm{d}} \mathrm{P}>0.05$ vs. normal gastric epithelial tissues.

resolved protein was transferred to a polyvinylidene difluoride membrane. The membrane was blocked in Tris-buffered saline (Fuzhou Maixin Biotech Development Co., Ltd.) supplemented with 5\% skim milk for $2 \mathrm{~h}$, and then incubated with primary antibody (rabbit anti-human TLR7 antibody; 1:200 dilution; catalog no., ab45371; Abcam) at $4^{\circ} \mathrm{C}$ overnight following by secondary antibody (goat anti-rabbit; 1:5,000 dilution; catalog no., MX20032; Fuzhou Maixin Biotechnology Development Co., Ltd.) for $2 \mathrm{~h}$ at $37^{\circ} \mathrm{C}$. The specific protein expression level was detected using an electrochemiluminescence kit (Santa Cruz Biotechnology, Inc., Dallas, TX, USA) in accordance with the manufacturer's protocol. The images were captured using a CAS-400SM chemiluminescence imaging system (Core Bio System, Seoul, Republic of Korea).

Statistical analysis. Data are expressed as mean \pm standard deviation. Statistical analysis was performed using SPSS

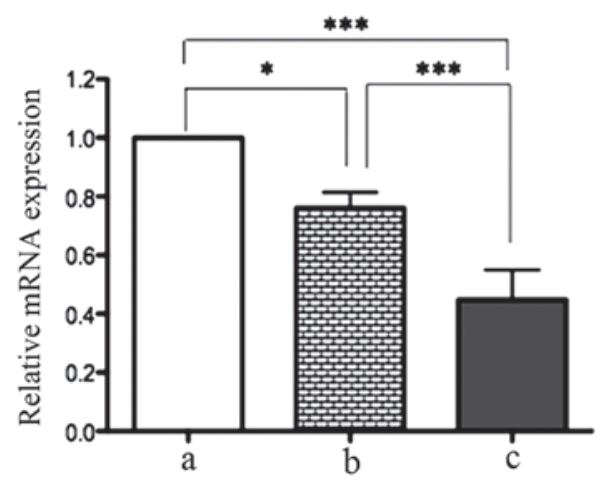

Figure 1. Toll-like receptor 7 (TLR7) mRNA expression in (a) gastric cancer; (b) cancer-adjacent; and (c) normal gastric epithelial tissues. TLR7 mRNA level was calculated as the fold-expression of TLR7 relative to the $\beta$-actin using $2^{-\Delta \Delta C}$ method. Data are presented as mean \pm standard deviation. ${ }^{*} \mathrm{P}<0.05 ;{ }^{* * *} \mathrm{P}<0.01$.

statistical software (version 16.0; SPSS Inc., Chicago, IL, USA). The differences between the measured data were compared using $t$-test and enumeration data were compared using the $\chi^{2}$ test. $\mathrm{P}<0.05$ was considered to indicate a statistically significant difference.

\section{Results}

TLR7 mRNA expression in different tissues. RT-qPCR demonstrated that there were significant differences in TLR7 mRNA expression among gastric cancer, cancer-adjacent tissues and normal gastric epithelial tissues. The TLR7 mRNA level in gastric cancer tissues was 0.24 -fold lower than that in cancer-adjacent tissues $(\mathrm{P}<0.05)$ and 0.76 -fold lower compared with normal gastric epithelial tissues $(\mathrm{P}<0.01)$. This indicates that TLR7 mRNA expression is downregulated in gastric cancer tissues (Fig. 1). 

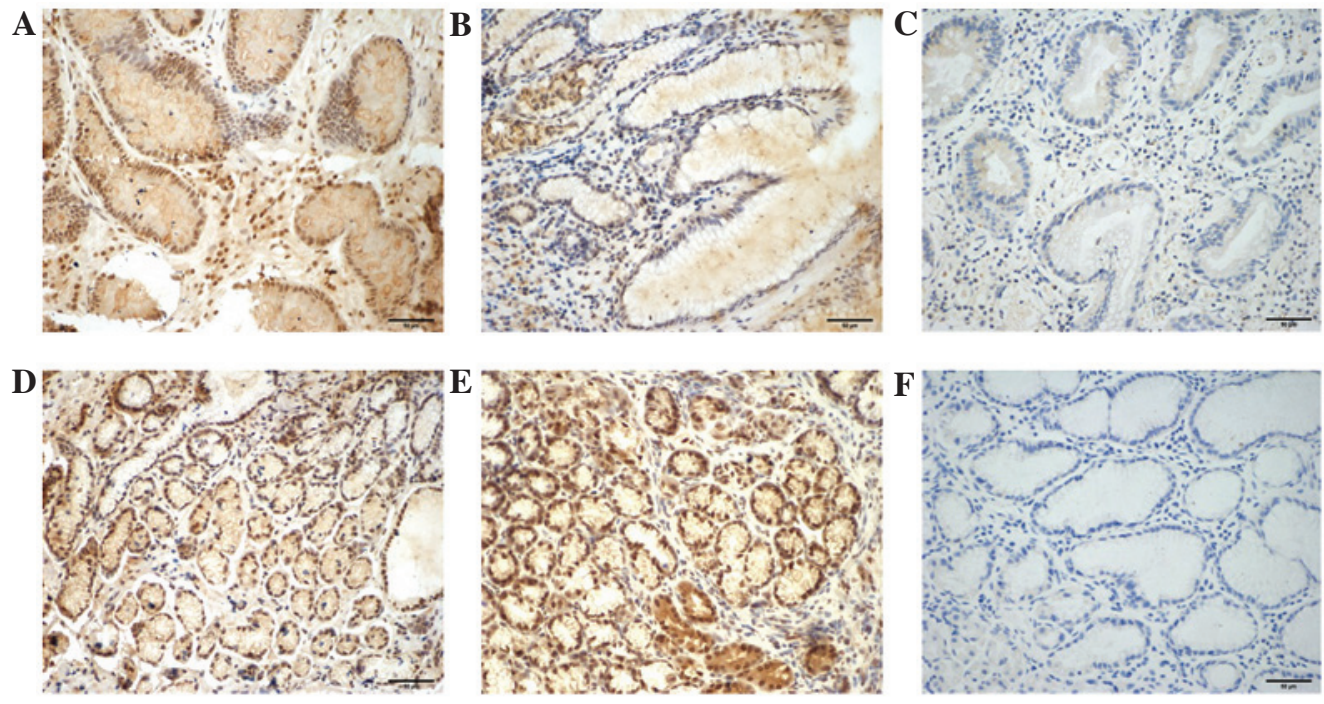

Figure 2. Toll-like receptor 7 (TLR7) protein expression in different tissues (3,3'-diaminobenzidine staining; magnification, x200). (A) Positive, (B) weak positive and (C) negative TLR7 expression in gastric cancer tissues samples. Strongly positive TLR7 expression in (D) cancer-adjacent tissues and (E) normal gastric epithelial tissues. (F) Negative control (phosphate-buffered saline was used to replace the primary antibody).

A

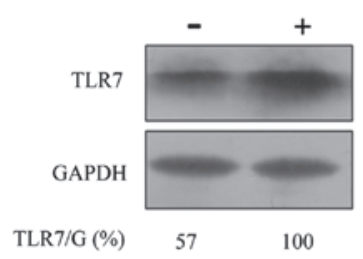

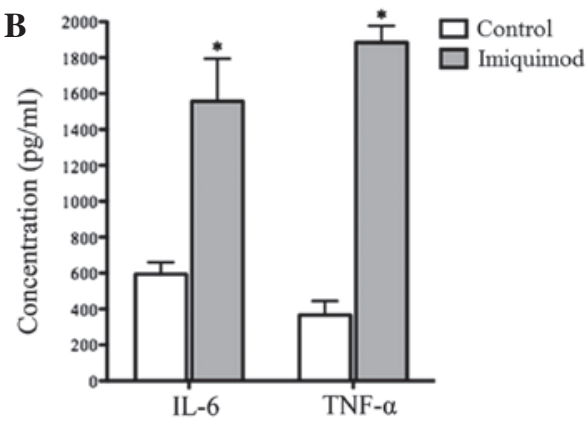

Figure 3. Effects of TLR7 agonist imiquimod on TLR7 protein expression and proinflammatory cytokine secretion in SGC-7901 cells. (A) The protein expression level of TLR7 was significantly enhanced after $24 \mathrm{~h}$ treatment with $100 \mu \mathrm{g} / \mathrm{ml}$ imiquimod. (B) Imiquimod induced the secretion of IL-6 and TNF- $\alpha$ in SGC-7901 cells. Data are presented as mean \pm standard deviation. "P<0.01 vs. the control (no imiquimod). TLR7 toll-like receptor 7; GAPDH, glyceraldehyde 3 -phosphate dehydrogenase; IL-6, interleukin-6; TNF- $\alpha$ tumor necrosis factor- $\alpha$.

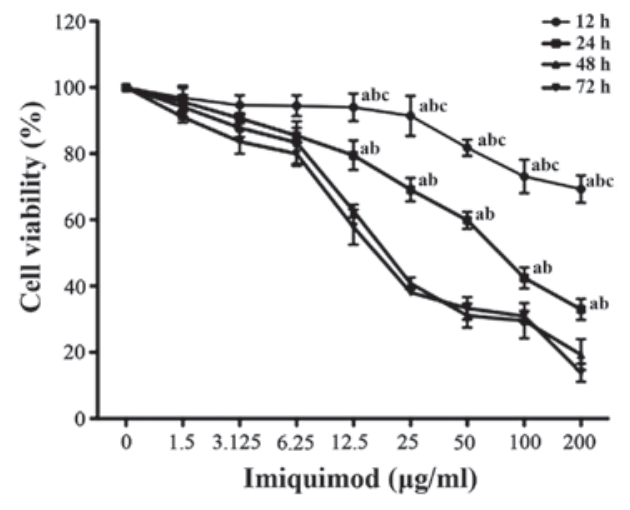

Figure 4. Effects of toll-like receptor 7 agonist imiquimod on the viability of SGC-7901 cells. Data are presented as mean \pm standard deviation. ${ }^{\mathrm{a}} \mathrm{P}<0.05$ vs. $72 \mathrm{~h},{ }^{b} \mathrm{P}<0.05$ vs. $48 \mathrm{~h},{ }^{\mathrm{c}} \mathrm{P}<0.05$ vs. $24 \mathrm{~h}$. $\mathrm{P}$-values were obtained from comparisons between tissues treated with $6.25,12.5,25,50$ and $100 \mu \mathrm{g} / \mathrm{ml}$ imiquimod for the same treatment duration.

TLR7 protein expression in different tissues. Immunohistochemistry results of TLR7 in the biopsies are presented in Fig. 2. TLR7 predominantly localized in the nucleus of glandular epithelial cells, as well as in inflammatory cells, such as lymphomonocytes. The expression level of TLR7 protein was markedly reduced in gastric cancer tissues compared with cancer-adjacent tissues. Certain gastric cancer biopsies even appeared to have a complete absence of TLR7 expression (Fig. 2C). As indicated in Table II, the IOD in gastric cancer tissues was significantly lower than that in cancer-adjacent and normal gastric epithelial tissues $(\mathrm{P}<0.01)$. Although TLR7 mRNA expression levels were higher in cancer-adjacent tissues compared with normal gastric epithelial tissues $(\mathrm{P}<0.05)$, no significant difference in TLR7 protein expression was observed between the two groups, as evaluated by IOD ( $>>0.05$; Table II). Furthermore, there was no significant difference in IOD between the diffuse type and intestinal type gastric cancer tissues $(\mathrm{P}>0.05$; Table II).

Effects of TLR7 agonist on TLR7 protein expression and proinflammatory cytokine secretion in SGC-7901 cells. Following $24 \mathrm{~h}$ of treatment with $100 \mu \mathrm{g} / \mathrm{ml}$ of TLR7 agonist imiquimod, the protein expression level of TLR7 was markedly enhanced (Fig. 3A). This indicates that TLR7 expression is activated by its agonist. To evaluate whether the upregulated TLR7 could 
exert a biological function, proinflammatory cytokines IL-6 and TNF- $\alpha$ were detected by ELISA assays in SGC-7901 cells treated with $100 \mu \mathrm{g} / \mathrm{ml}$ imiquimod for $24 \mathrm{~h}$ As indicated in Fig. 3B, imiquimod significantly increased the secretion of IL-6 and TNF- $\alpha$ in SGC-7901 cells compared with the control (no imiquimod treatment; $\mathrm{P}<0.01$ ). This indicates that the activation of TLR7 may induce a biological effect, such as an immune response.

Effects of TLR7 agonist on the viability of SGC-7901 cells. SGC-7901 cells were treated with various doses of imiquimod for 12, 24, 48 and $72 \mathrm{~h}$. Cell viability was assessed by performing an MTT assay. As indicated in Fig. 4, imiquimod significantly reduced the viability of SGC-7901 cells in a dose- and time-dependent manner. Treatment with imiquimod $(100 \mu \mathrm{g} / \mathrm{ml})$ for $24 \mathrm{~h}$ led to an $\sim 72 \%$ inhibition in proliferation of SGC-7901 cells. This indicates that the activation of TLR7 may inhibit the proliferation of gastric cancer cells.

\section{Discussion}

The majority of TLRs are expressed in gastric cancer tissues. For example, Schmausser et al (15) reported that TLR4, TLR5 and TLR9 can be detected in lesions of intestinal metaplasia and dysplasia, as well as gastric cancer. Notably, TLR7 expression has not yet been identified in any gastric cell lines or tissues. The present study, to the best of our knowledge, is the first prospective research that evaluates the expression levels of TLR7 in patients with gastric cancer.

TLR7 expression and function in tumorigenesis have been examined in several types of cancer, including lung, esophageal, colon and liver cancer. TLR7 expression is significantly increased in non-small cell lung cancer compared with normal bronchoscopic controls (18). In one study of esophageal squamous cell carcinoma, only $9.2 \%$ of normal controls were TLR7-positive, in contrast to 50\% TLR7-positive cases of esophageal squamous cell carcinoma (19). Conversely, TLR7 expression was lower in hyperplastic and tubulovillous adenoma polyps from patients with colorectal carcinoma, indicating a possible protective role of TLR7 against malignant transformation in colorectal mucosa (20). Furthermore, TLR7 mRNA is markedly expressed in RWPE-1 non-cancerous prostate epithelial cells, but not in PC3 and DU145 prostate cancer cells (21). Furthermore, a recent study revealed that TLR7 is significantly downregulated in hepatocellular carcinoma; in particular, patients with hepatitis B viral infection may induce interferon- $\gamma($ IFN- $\gamma)$ release to inhibit TLR7 expression, resulting in immune escape and even immunological tolerance (22). Thus, TLR7 may differently act on tumorigenesis depending on the tumor origin. The present study demonstrated that gastric cancer tissues exhibit significantly lower mRNA and protein levels of TLR7 compared with cancer-adjacent or normal gastric epithelial tissues. This indicates that downregulated TLR7 expression may contribute to the promotion of gastric carcinogenesis; however, the mechanism is unknown.

The function of TLR7 agonists in tumorigenesis has been examined in several types of cancer. Imiquimod is a synthetic agonist of TLR7 that has been used as a topical therapy for certain skin neoplasms, such as basal cell carcinoma (23). The present study identified that TLR7 expression is promoted following stimulation with its agonist imiquimod, and the secretion of proinflammatory cytokines IL-6 and TNF- $\alpha$ in gastric cancer cells increases in response to imiquimod. Thus, it appears that the activation of TLR7 can induce biological effects and may exert immune function in gastric cancer cells. Evidence from previous studies indicates that stimulation of TLR expression in tumor cells can promote inflammation and cell survival in the tumor microenvironment, and further lead to tumor progression (24-26). However, in the present study, the viability of SGC-7901 cells decreased when the supernatant was supplemented with imiquimod, suggesting that a direct cytotoxic effect was induced by imiquimod. There may be two reasons for this. First, imiquimod may induce programmed death of gastric cancer cells, such as autophagy and apoptosis. Accumulating evidence indicates that TLR7 activity is not restricted to the elicitation of innate and adaptive immune responses, but directly triggers programmed cell death in various types of cancer, such as melanoma and colon cancer $(16,27)$. Second, TLR7 is selectively expressed in plasmacytoid dendritic cells (pDCs). When TLR7 is activated, pDCs are capable of secreting very high levels of type I IFNs in response to pathogenic agents or danger signals. TLR7 agonists can effectively induce pDC maturation, resulting in the induction of an inflammatory response that contributes to the elimination of tumor cells (28). Further studies are required to better define the distinct role of TLR7 in gastric tumorigenesis.

In conclusion, the expression of TLR7 is decreased in gastric cancer tissues, and TLR7 activation appears to enhance TLR7 expression, promote the production of proinflammatory cytokines and reduce the viability of gastric cancer cells. The present study has provided a basis for investigation into the molecular mechanism of gastric cancer, and the application of the TLR7 agonist imiquimod as a treatment modality. However, the mechanisms of cell apoptosis are complex, and numerous pathways are involved. Therefore, the mechanism of imiquimod-induced gastric cancer cell apoptosis requires further study.

\section{References}

1. Akira $\mathrm{S}$ and Takeda K: Toll-like receptor signalling. Nat Rev Immunol 4: 499-511, 2004.

2. Curtin JF, Liu N, Candolfi M, Xiong W, Assi H, Yagiz K, Edwards MR, Michelsen KS, Kroeger KM, Liu C, et al: HMGB1 mediates endogenous TLR2 activation and brain tumor regression. PLoS Med 6: e10, 2009.

3. Goto Y, Arigami T, Kitago M, Nguyen SL, Narita N, Ferrone S, Morton DL, Irie RF and Hoon DS: Activation of Toll-like receptors 2, 3 and 4 on human melanoma cells induces inflammatory factors. Mol Cancer Ther 7: 3642-3653, 2008.

4. Ilvesaro JM, Merrell MA, Swain TM, Davidson J, Zayzafoon M, Harris KW and Selander KS: Toll like receptor-9 agonists stimulate prostate cancer invasion in vitro. Prostate 67: 774-781, 2007.

5. Xie W, Wang Y, Huang Y, Yang H, Wang J and Hu Z: Toll-like receptor 2 mediates invasion via activating NF-kappaB in MDA-MB-231 breast cancer cells. Biochem Biophys Res Commun 379: 1027-1032, 2009.

6. Sato Y, Goto Y, Narita N and Hoon DS: Cancer cells expressing toll-like receptors and the tumor microenvironment. Cancer Microenviron 2 (Suppl 1): S205-S214, 2009.

7. Wolska A, Lech-Marańda E and Robak T: Toll-like receptors and their role in carcinogenesis and anti-tumor treatment. Cell Mol Biol Lett 14: 248-272, 2009.

8. Rakoff-Nahoum S and Medzhitov R: Toll-like receptors and cancer. Nat Rev Cancer 9: 57-63, 2009. 
9. Brenner H, Rothenbacher D and Arndt V: Epidemiology of stomach cancer. Methods Mol Biol 472: 467-477, 2009.

10. Jemal A, Bray F, Center MM, Ferlay J, Ward E and Forman D: Global cancer statistics. CA Cancer J Clin 61: 69-90, 2011.

11. Chen W, Zheng R, Zhang S, Zhao P, Li G, Wu L and He J: Report of incidence and mortality in China cancer registries, 2009. Chin J Cancer Res 25: 10-21, 2013

12. Crew KD and Neugut AI: Epidemiology of gastric cancer. World J Gastroenterol 12: 354-362, 2006.

13. Ferlay J, Shin HR, Bray F, Forman D, Mathers C and Parkin DM: Estimates of worldwide burden of cancer in 2008: GLOBOCAN 2008. Int J Cancer 127: 2893-2917, 2010.

14. Killeen SD, Wang JH, Andrews EJ and Redmond HP: Exploitation of the Toll-like receptor system in cancer: A doubled-edged sword? Br J Cancer 95: 247-252, 2006.

15. Schmausser B, Andrulis M, Endrich S, Müller-Hermelink HK and Eck M: Toll-like receptors TLR4, TLR5 and TLR9 on gastric carcinoma cells: An implication for interaction with helicobacter pylori. Int J Med Microbiol 295: 179-185, 2005.

16. Yi JY, Jung YJ, Choi SS, Hwang J and Chung E: Autophagy-mediated anti-tumoral activity of imiquimod in Caco-2 cells. Biochem Biophys Res Commun 386: 455-458, 2009.

17. Livak KJ and Schmittgen TD: Analysis of relative gene expression data using real-time quantitative PCR and the 2(-Delta Delta C(T)) Method. Methods 25: 402-408, 2001.

18. Cherfils-Vicini J, Platonova S, Gillard M, Laurans L, Validire P, Caliandro R, Magdeleinat P, Mami-Chouaib F, Dieu-Nosjean MC, Fridman WH, et al: Triggering of TLR7 and TLR8 expressed by human lung cancer cells induces cell survival and chemoresistance. J Clin Invest 120: 1285-1297, 2010.

19. Sheyhidin I, Nabi G, Hasim A, Zhang RP, Ainiwaer J, Ma H and Wang H: Overexpression of TLR3, TLR4, TLR7 and TLR9 in esophageal squamous cell carcinoma. World J Gastroenterol 17: $3745-3751,2011$
20. Eiró N, González L, González LO, Andicoechea A, Fernández-Díaz M, Altadill A and Vizoso FJ: Study of the expression of toll-like receptors in different histological types of colorectal polyps and their relationship with colorectal cancer. J Clin Immunol 32: 848-854, 2012.

21. Han JH, Park SY, Kim JB, Cho SD, Kim B, Kim BY, Kang MJ, Kim DJ, Park JH and Park JH: TLR7 expression is decreased during tumour progression in transgenic adenocarcinoma of mouse prostate mice and its activation inhibits growth of prostate cancer cells. Am J Reprod Immunol 70: 317-326, 2013.

22. Lin KJ, Lin TM, Wang CH, Liu HC, Lin YL and Eng HL: Down-regulation of Toll-like receptor 7 expression in hepatitis-virus-related human hepatocellular carcinoma. Hum Pathol 44: 534-541, 2013

23. Sligh JE Jr: New therapeutic options for actinic keratosis and basal cell carcinoma. Semin Cutan Med Surg 33 (Suppl 4): S76-S80, 2014.

24. Yu L and Chen S: Toll-like receptors expressed in tumor cells: Targets for therapy. Cancer Immunol Immunother 57: 1271-1278, 2008.

25. Kelly MG, Alvero AB, Chen R, Silasi DA, Abrahams VM, Chan S, Visintin I, Rutherford T and Mor G: TLR-4 signaling promotes tumor growth and paclitaxel chemoresistance in cancer. Cancer Res 66: 3859-3868, 2006.

26. Smith MF Jr, Mitchell A, Li G, Ding S, Fitzmaurice AM, Ryan K, Crowe $\mathrm{S}$ and Goldberg JB: Toll-like receptor (TLR) 2 and TLR5, but not TLR4, are required for Helicobacter pylori induced NF-kappa B activation and chemokine expression by epithelial cells. J Biol Chem 278: 32552-32560, 2003.

27. Huang SW, Liu KT, Chang CC, Chen YJ, Wu CY, Tsai JJ, Lu WC, Wang YT, Liu CM and Shieh JJ: Imiquimod simultaneously induces autophagy and apoptosis in human basal cell carcinoma cells. Br J Dermatol 163: 310-320, 2010.

28. Aspord C, Tramcourt L, Leloup C, Molens JP, Leccia MT, Charles $\mathrm{J}$ and Plumas J: Imiquimod inhibits melanoma development by promoting pDC cytotoxic functions and impeding tumor vascularization. J Invest Dermatol 134: 2551-2561, 2014. 